\title{
Currículo e Educação Matemática: o que pensam um grupo de estudantes de pós-graduação
}

\author{
Maria Elizabete de Souza Couto ${ }^{1}$ \\ Zulma Elizabete de Freitas Madruga ${ }^{2}$
}

\section{RESUMO}

Este artigo objetiva compreender como estudantes de pós-graduação em Educação Matemática percebem o currículo, no contexto do próprio currículo e nas suas relações com a Educação Matemática. Trata-se de uma pesquisa qualitativa, com a participação de 26 alunos de mestrado em Educação Matemática de uma universidade pública do sul da Bahia. Na disciplina de Matemática, Currículo e Diversidade Cultural, os estudantes escreveram sobre o que pensavam acerca do currículo e do currículo de Matemática. Como método de análise dos dados, foi utilizada a Análise Textual Discursiva (ATD). Os resultados indicam que os alunos percebem o currículo de três formas diferentes: como documento/parâmetros; como lista de conteúdos; e como saberes e desenvolvimento de competências e habilidades. No que se refere ao currículo de Matemática, expressam a ideia de uma área abstrata, com pouca ou nenhuma relação com a realidade, sugerindo uma teoria tradicional na qual pouco prioriza a diversidade e/ou a interdisciplinaridade.

PALAVRAS-CHAVE: Educação Matemática. Currículo. Currículo de Matemática. Percepção de estudantes.

Curriculum and Mathematical Education: What a Group of Graduate Students Think

\footnotetext{
${ }^{1}$ Doutora em Educação. Universidade Estadual de Santa Cruz - UESC, Ilhéus, Bahia, Brasil. https://orcid.org/00000002-0026-5266.melizabetesc@gmail.com.

${ }^{2}$ Doutora em Educação em Ciências e Matemática.Universidade Federal do Recôncavo da Bahia - UFRB, Amargosa, Bahia, Brasil. https://orcid.org/0000-0003-1674-0479.betemadruga@ufrb.edu.br.
} 


\begin{abstract}
This article aims to understand how postgraduate students in Mathematics Education perceive the curriculum, in the context of the curriculum itself and in its relations with Mathematical Education. This is a qualitative research, with the participation of 26 master's students in Mathematical Education from a public university in southern Bahia. In the Mathematics, Curriculum and Cultural Diversity course, students wrote about what they thought about the Mathematics curriculum and curriculum. As data analysis method, the Discursive Textual Analysis (ATD) was used. The results indicate that students perceive the curriculum in three different ways: as document / parameters; as content; and how to know and develop skills and abilities. Concerning the Mathematics curriculum, they express the idea of an abstract area, with little or no relation to reality, suggesting a traditional theory in which little priority is given to diversity and / or interdisciplinarity.
\end{abstract}

KEYWORDS: Mathematical education. Curriculum. Mathematics curriculum. Perception of students.

\title{
Currículo y Educación Matemática: lo que piensa un grupo de estudiantes de Postgrado
}

\section{RESUMEN}

Este artículo tiene como objetivo comprender cómo los estudiantes de posgrado en Educación Matemática perciben el currículo, en el contexto del currículo mismo y en sus relaciones con la Educación Matemática. Esta es una investigación cualitativa, con la participación de 26 estudiantes de maestría en Educación Matemática de una universidad pública en el sur de Bahía. En el curso de Matemáticas, Currículo y Diversidad Cultural, los estudiantes escribieron sobre lo que pensaban sobre el currículo y el currículo de Matemáticas. Como método de análisis de datos, se utilizó el análisis textual discursivo (ATD). Los resultados indican que los estudiantes perciben el plan de estudios de tres maneras diferentes: como documento / parámetros; como contenido; y cómo saber y desarrollar habilidades y destrezas. Con respecto al plan de estudios de Matemáticas, expresan la idea de un área abstracta, con poca o ninguna relación con la realidad, sugiriendo una teoría tradicional en la que se da poca prioridad a la diversidad y / o interdisciplinariedad. 
PALABRAS CLAVE: Educación matemática. Currículo. Currículo de las matemáticas. Percepción de los alumnos.

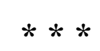

\section{Introdução}

O currículo e a Matemática são temáticas presentes no contexto da escola, porém, não são tratadas como almejam algumas pesquisas científicas, tornando-as por vezes distantes das situações de ensino e de aprendizagem. Entretanto, o currículo é o lugar/espaço em que as ações são planejadas considerando o 'por que', 'para que', 'quem' e 'onde' desenvolver aquelas ações, tendo em vista a formação de estudantes, professores e comunidade, nas diferentes áreas do conhecimento que tem como campo de pesquisa a formação de professores.

As discussões sobre currículo fazem parte do contexto da educação, no Brasil, há quase 100 anos, mas parece ainda ser um território ora pensado em relação à proposição teórica e metodológica, ora em busca de identificação para organizá-lo. Tais estudos começaram a ser estruturados no período pósprimeira guerra mundial, quando muitas transformações sociais, políticas, ideológicas e econômicas começaram a acontecer com início do processo de industrialização. Essa situação requeria pessoas para trabalhar na indústria que vieram, na sua maioria, do campo. O trabalho na indústria impulsionou uma busca por pessoas para atender as vagas e exigiu outro tipo de sociedade, isto é, um cidadão alfabetizado, que dominasse a leitura, escrita e a Matemática. Nesse sentido, a alfabetização foi considerada fundamental. Naquele momento, já ficava estabelecido um tipo de currículo para atender as necessidades da indústria.

Pensar qual seria a Matemática a ser ensinada para atender a essas necessidades da época, parece que ainda é o dilema até os dias atuais. Assim, na perspectiva de aproximação entre o currículo e a Matemática, tem-se o 
seguinte questionamento: como os estudantes de pós-graduação em Educação Matemática percebem o currículo, no contexto do próprio currículo e nas relações com o ensino e a aprendizagem de Matemática? A partir deste questionamento, essa pesquisa foi realizada com o objetivo de compreender como estudantes de pós-graduação em Educação Matemática percebem o currículo, no contexto do próprio currículo e nas suas relações com o ensino e a aprendizagem de Matemática.

\section{O currículo e a Matemática X a Matemática e o currículo}

Os estudos sobre currículo já desenvolvidos nos Estados Unidos foram fundamentados principalmente nas ideias do pragmatismo, em teorias elaboradas na Europa e com as contribuições da Psicologia. Naquele momento, o modelo da Escola Nova (John Dewey) foi a base para tal mudança, a qual pretendia educar para a vida, mas não houve uma proposta organizada de currículo. Entretanto, as ideias adotadas eram caracterizadas com: "(a) ênfase em disciplinas literárias e acadêmicas; (b) enciclopedismo e (c) divisão entre trabalho manual e intelectual" (FIGUEIREDO, 1981, apud PARAÍSO, 2010, p. 63). Outra característica era "a natureza do processo escolar e sugerindo a renovação do currículo, dos métodos de ensino e da avaliação e, ainda, a democratização da sala de aula e da relação professor-aluno" (FIGUEIREDO, 1981 apud PARAÍSO, 2010, p. 63). De uma maneira geral, para Dewey a educação deveria ser vista como "processo de reconstrução e reorganização da experiência, pelo qual lhe percebemos mais agudamente o sentido, e com isso, nos habilitamos a melhor dirigir o curso de nossas experiências futuras" (1971, p. 17), para que a sociedade possa se organizar, crescer e desenvolver.

Na década de 1960, surgiu a defesa de um currículo organizado por áreas, com programas que atendessem uma sequência de objetivos comportamentais, conteúdos, atividades e avaliação, com base na teoria do reforço (Behaviorismo - Skinner), que sugeria um ensino programado, com 
previsão do comportamento desejável e o produto final. Uma tendência tecnicista, propondo ensino e, consequentemente, um currículo fundamentado nos princípios da racionalidade, eficiência, eficácia e produtividade (BEHRENS, 2011). Os aspectos sociais e políticos não eram explicitados. Assim, o currículo dos cursos era caracterizado por treinamentos, oferecendo primeiro as disciplinas teóricas e depois as práticas, marcando assim, a distância entre teoria e prática.

Nesse período, com o golpe de 1964, outras transformações sociais e políticas ocorreram, e a educação continuou sendo um recurso fundamental para o crescimento do país, embora seja um modelo baseado no tecnicismo e no produto.

Nos anos de 1970, a presença das ideias tecnicistas foi marcante, porém surgiram orientações humanistas fundamentadas no não diretivismo (Carl Rogers). Uma década marcada pelo discurso híbrido sobre currículo (PARAÍSO, 2010). Nesse período os estudos sobre currículo no Brasil começaram a ser consolidados e entrava em pauta mais um tema, o planejamento.

Enquanto isso, na segunda metade desta década, o discurso acerca do currículo tem as marcas do tecnicismo. Paraíso (2010, p. 75) mostra que "as atenções desviam-se para a operacionalização e para a classificação de objetivos educacionais, bem como para procedimentos de instrução individualizada e de educação programada”.

Na década de 1980, período pós-ditadura militar, as ideias e propostas da pedagogia crítica começaram a aflorar e influenciar novas maneiras de pensar o currículo, com influência dos estudos de Michel Apple e Henri Giroux. Para Apple "o currículo não pode ser compreendido - e transformado - se não fizermos perguntas fundamentais sobre suas conexões com relação ao poder" (SILVA, 2005, p. 47-49), tais como: "Por que esses conhecimentos e não outros? Por que esse conhecimento é considerado importante e não outros? [...] trata-se do conhecimento de quem?" (SILVA, 2005, p. 47-49). Para Apple (2006) educação, política e cultura caminham juntas, e o currículo não 
é neutro. O conhecimento estudado nas escolas é resultado de tensões e compromissos políticos, sociais, econômicos e culturais, na tentativa de organizar e desorganizar as pessoas.

Henri Giroux já pensava em uma "pedagogia da possibilidade” com "três conceitos centrais: esfera pública, intelectual transformador e voz" (SILVA, 2005, p. 53-54). A voz sugere um papel ativo à participação para contestar as relações de poder. Dessa maneira, o currículo "é um local onde, ativamente, se produzem e se criam significados sociais" (SILVA, 2005, p. 55). As questões políticas e sociais estarão sempre em evidência no currículo, orientando as perguntas e dando pistas para as respostas.

A partir de 1990, novas influências e temas deram corpo a novas possibilidades para organizar um currículo, fundamentado na teoria da complexidade (MORIN, 2003), em uma sociedade marcada pela globalização, pelas certezas, incertezas, urgências; e dúvidas. Tal situação gerou uma crise nos valores e, certamente, na educação, considerando que "é preciso substituir um pensamento que isola e separa por um pensamento que distingue e une. É preciso substituir um pensamento disjuntivo e redutor por um pensamento do complexo, no sentido originário do termo complexus: o que é tecido junto" (MORIN, 2003, p. 89).

Esse pensamento que distingue e une, sugere uma ligação entre o local e o global, em uma perspectiva de romper fronteiras de conhecimentos. No contexto de interlocução, os estudos culturais concebem a cultura como "um campo de produção de significados no qual os diferentes grupos sociais, situados em posições diferenciais de poder, lutam pela imposição de seus significados à sociedade mais ampla" (SILVA, 2005, p. 133-134) que se configuram como campo contestado de significados, o que se constituiu em conceitos na organização dos pressupostos das teorias pós-crítica do currículo.

No século XXI, com o avanço das tecnologias, a rapidez das informações vem exigindo mudanças na maneira de pensar, trabalhar, viver e construir o conhecimento, carregando as marcas das relações sociais de poder em um território político e influenciando um currículo que se traduza como 
documento de identidade (SILVA, 2005). Assim, o desenho de um currículo implica em uma sequência de pensamentos, da formação e da prática pedagógica em uma perspectiva contextualizada.

Imersos neste contexto, no início deste século, vários movimentos da sociedade civil, associações, professores-pesquisadores em universidades mobilizados pelas ideias emergentes na sociedade, começaram a pensar ser necessário questionar e refletir sobre o currículo, o conhecimento, a sociedade, o ensino e a aprendizagem em uma nova perspectiva. Após a Lei de Diretrizes e Bases da Educação Nacional - LDB 9394/96, foi aprovada as Diretrizes Curriculares Nacionais para o ensino de Matemática indicando o profissional que se espera formar e sugerindo opções para organizar o currículo, devendo "ser elaborados de maneira a desenvolver as seguintes competências e habilidades" (BRASIL, 2001, p. 3).

a) capacidade de expressar-se escrita e oralmente com clareza e precisão;

b) capacidade de trabalhar em equipes multi-disciplinares;

c) capacidade de compreender, criticar e utilizar novas ideias e tecnologias para a resolução de problemas;

d) capacidade de aprendizagem continuada, sendo sua prática profissional também fonte de produção de conhecimento;

e) habilidade de identificar, formular e resolver problemas na sua área de aplicação, utilizando rigor lógico-científico na análise da situação-problema;

f) estabelecer relações entre a Matemática e outras áreas do conhecimento;

g) conhecimento de questões contemporâneas;

h) educação abrangente necessária ao entendimento do impacto das soluções encontradas num contexto global e social;

i) participar de programas de formação continuada;

j) realizar estudos de pós-graduação;

k) trabalhar na interface da Matemática com outros campos de saber. (BRASIL, 2001, p. 3-4). 
Embora imersos em um contexto das diferenças e dos estudos culturais, as diretrizes propõem um currículo baseado no desenvolvimento de competências e habilidades, atendendo a uma perspectiva neoliberal, isto é, "um sistema de avaliação quantitativa que pretende, principalmente, classificar as escolas e controlar, mais recentemente o trabalho docente". [...] dando ênfase à "valorização do indivíduo, de sua capacidade de iniciativa e de seu espírito de competitividade", (PARAISO, 2010, p. 121-122), na perspectiva de atender as necessidades de uma sociedade tecnologizada.

Nesse sentido, desenvolver competências e habilidades começaram a ser palavras de ordem. Sendo assim, as competências são "um conjunto de saberes e habilidades que os aprendentes incorporam por meio da formação e da experiência, conjugados à capacidade de integrá-los, utilizá-los, transferilos em diferentes situações" (MACEDO, 2009, p. 93), para serem transformados em saberes em uso, tendo como meta o desenvolvimento de várias competências, entre elas "[...] aprendizagem para e pelas situações e cenários de trabalho; tradução dos conteúdos em objetivos flexíveis; [...]" (MACEDO, 2009, p. 94), valorizando o desenvolvimento de competências com a organização da formação e do currículo, avançando nos aspectos políticos, sociais, culturais e éticos.

Isto porque "as competências são, ao mesmo tempo, de ordem cognitiva, afetiva, conativa e prática", começando a pensar o currículo e a formação para além do aspecto psicológico (MACEDO, 2009; PAQUAY et al, 2001).

As orientações publicadas nas Diretrizes Curriculares Nacionais para o ensino de Matemática (BRASIL, 2001) indicaram às instituições de ensino superior a necessidade de rever os currículos dos cursos, o que exigiu uma (re)elaboração. Essa ação sugeriu uma pergunta, como a já feita por VeigaNeto (2002, p. 166): “como deverão ser planejados, organizados e implementados os currículos de modo que a escola possa dar melhores respostas às mudanças do mundo contemporâneo?" como forma de problematizar o ensino, a aprendizagem e a formação profissional, nesse caso, 
de futuros professores de Matemática, olhando, escutando, refletindo e compreendendo as novas 'formas' (geometrias), (VEIGA-NETO, 2002). E os novos processos identitários nos diferentes tempos e espaços, bem como possibilidades de pensar o currículo com várias estruturas: por projetos, problemas, temas geradores, módulos, em rede e hipertextual, em ciclos de formação (MACEDO, 2009), em uma dimensão inter e/ou transdisciplinar.

E em relação à Matemática, essas várias formas (geometrias) (VEIGANETO, 2002) indicam diversas possibilidades para organizar um currículo o qual "abre espaços para compreendermos a pluralidade de saberes que circulam no contexto social. Mais que isso, permite conceber que a recontextualização pode se desenvolver pela produção de híbridos culturais" (LOPES; MACEDO, 2011, p. 106).

No que tange à Educação Matemática, durante a década de 1990, Kilpatrick (1998), refere-se às 'mudanças curriculares' como uma tendência de temática mundial. No entanto, as pesquisas sobre currículo são relativamente instáveis, caracterizando, assim, a sociedade, o que também influencia a construção e organização do currículo.

$\mathrm{Na}$ área de Educação Matemática, a presença do termo currículo nas nomeações dos grupos de pesquisa não é tão frequente. É possível conjecturar que, em grande parte das investigações na área de Educação Matemática, o currículo aparece em pesquisas com outros focos, contudo não é abordado como um objeto de investigação em si mesmo. Outro aspecto observável é o ainda pequeno diálogo entre tendências curriculares na área de Educação e na de Educação Matemática. (PIRES et al, 2014, p. 486)

Por outro lado, no momento atual, baseando-se na tendência da Educação Matemática, o currículo é movimento, com orientações que indicam "um conhecimento em vaivém, que progride indo das partes ao todo e do todo às partes: o que é nossa ambição comum" (MORIN, 2003, p. 116), em conexão com os temas da contemporaneidade. 


\section{Os caminhos metodológicos}

Esta pesquisa fundamenta-se na abordagem qualitativa (BOGDAN; BIKLEN, 2010) como orientação à sua realização. Para a produção do material empírico foram adotadas narrativas/depoimentos de 26 estudantes de um programa de Pós-Graduação em Educação Matemática, em uma instituição pública, na disciplina Matemática, Currículo e Diversidade Cultural, considerando que "realizar estudos de pós-graduação" (BRASIL, 2001, p. 4) é uma das competências na formação do professor de Matemática.

Os estudantes são graduados/licenciados em Matemática. Para preservar a identidade, os alunos foram identificados da seguinte maneira: Al.1, Al.2, Al.3... Al.26.

No material empírico, os estudantes explicitaram o que pensam sobre currículo e o currículo de Matemática, de forma livre e sem comentário anterior sobre o assunto, na primeira aula da disciplina do segundo semestre de 2017 e 2018. Na escrita, mobilizaram conhecimentos que fazem parte da formação de professores: da matéria de ensino (matemática), pedagógico, dos alunos e do currículo que são adquiridos na graduação e no contexto das escolas onde lecionam.

Para análise desse material foi utilizada a Análise Textual Discursiva - ATD, (MORAES; GALIAZZI, 2013). Esse tipo de análise “[...] pode ser compreendida como um processo auto-organizado de construção de compreensão em que novos entendimentos emergem [para] captar do novo emergente em que a nova compreensão é comunicada e validada” (MORAES, 2002, p. 192).

Os depoimentos dos estudantes foram analisados conforme as três etapas propostas por Moraes e Galiazzi (2013): desmontagem dos textos (unitarização); estabelecimento de relações (categorização); e captação do novo emergente (produção de metatextos).

A unitarização implicou em examinar o material em seus detalhes, 
"fragmentando-o no sentido de atingir unidades constituintes, enunciados referentes aos fenômenos estudados" (MORAES, 2003, p. 191). Nesta etapa, as narrativas dos estudantes foram separadas por ideias, em unidades de sentido para posteriormente serem agrupadas.

Na categorização ocorreu o 'agrupamento' das unidades de significado (ou sentido) elencadas na fase anterior, implicou em "construir relações entre as unidades de base, combinando-as e classificando-as no sentido de compreender como esses elementos unitários podem ser reunidos na formação de conjuntos mais complexos, as categorias" (MORAES, 2003, p. 191).

A etapa seguinte foi a elaboração de um texto interpretativo (metatexto), emergente desse processo.

A intensa impregnação nos materiais da análise desencadeada pelos dois estágios anteriores possibilita a emergência de uma compreensão renovada do todo. O investimento na comunicação dessa nova compreensão, assim como de sua crítica e validação, constituem o último elemento do ciclo de análise proposto. $\mathrm{O}$ metatexto resultante desse processo representa um esforço em explicitar a compreensão que se apresenta como produto de uma nova combinação dos elementos construídos ao longo dos passos anteriores. (MORAES, 2003, p. 191)

Ao final dessas três etapas, mediante um processo de leitura, releitura e interpretação do material, a análise dos dados foi organizada em duas grandes categorias emergentes: Percepções sobre o Currículo; e Percepções sobre o Currículo de Matemática, as quais serão explicitadas a seguir.

\section{Percepções sobre Currículo}

Nas narrativas dos estudantes, durante o processo de análise, observaram-se diferentes maneiras de compreensões sobre o currículo. $\mathrm{Na}$ categorização das unidades de significado, bem como na elaboração dos 
metatextos, essas compreensões foram chamadas de percepções

De acordo com Mariotti (2007), a percepção é um fenômeno que ocorre na estrutura dos seres vivos. Para o autor, o mundo externo é o mesmo, mas o universo interno difere de pessoa para pessoa. A realidade é o que a pessoa percebe, tanto objetiva quanto subjetivamente, é o que ela observa, sente e pensa em relação ao fenômeno observado (MARIOTTI, 2007).

Em termos fisiológicos, a percepção ocorre por meio dos cinco sentidos. [...]. Mas seus resultados internos, subjetivos, dependem das peculiaridades de cada um, isto é, da estrutura individual, em especial a do sistema nervoso. Essa estrutura é complexa: em sua constituição entram fatores como a educação, a cultura, o contexto histórico-social e nossas emoções num dado instante. (MARIOTTI, 2007, p. 17)

Para George (1973, p. 27), "percepção de uma forma geral significa o processo completo de recebimento de informações (seja sua proveniência do meio interno e/ou do meio externo)." Em outras palavras, percepção é o processo de interpretação dos estímulos provenientes do meio ambiente. Segundo George, "percepção pode ser considerada como estreitamente relacionada com o pensamento, resolução de problemas e processos decisórios" (GEORGE, 1973, p. 51).

De acordo com Biembengut (2014), percepção é um processo complexo que consiste em receber, identificar e classificar informações provenientes do meio ou do próprio corpo. Assim, a percepção pode ser considerada como "a primeira fonte de conhecimento necessária para que se possa fazer uma descrição do meio, uma decodificação e representação. [...] tem relação com o pensamento, com a resolução de problemas e com os processos de decisão das pessoas". (MADRUGA, 2016, p. 50). Nesse sentido, entende-se que a maneira com que os estudantes compreendem currículo, na verdade são percepções dos mesmos sobre o tema, visto que relataram não terem estudos aprofundados sobre currículo no período da graduação. Como tratava-se da primeira aula 
da disciplina do mestrado, essas discussões ainda estavam por vir. Assim, destas percepções, foi possível elencar três subcategorias sobre currículo, explicitadas no Quadro 1, a seguir. Cabe destacar que alguns alunos apresentaram mais de uma percepção.

Quadro 1: Percepções dos alunos

\begin{tabular}{|c|l|c|}
\hline $\mathbf{N}^{\mathbf{0}}$ & \multicolumn{1}{|c|}{ Percepções dos alunos sobre currrículo } & $\begin{array}{c}\text { Quantidade } \\
\text { de alunos }\end{array}$ \\
\hline 01 & Documento/parâmetros & 15 \\
\hline 02 & Conteúdos & 12 \\
\hline 03 & Saberes e desenvolvimento de competências e habilidades & 05 \\
\hline
\end{tabular}

Fonte: Material produzido na pesquisa.

Com base nestas três subcategorias, passa-se à uma discussão de cada uma delas, com o intuito de explicitar as compreensões, ou seja, percepções dos estudantes de pós-graduação.

\section{Currículo como documento/parâmetros}

As narrativas indicam que o currículo enquanto documento orienta, descreve e direciona a formação, considerando a realidade daquela comunidade. Entretanto, pensam a formação apenas para os alunos, enquanto que as ações de formação continuada dos professores devem estar descritas no currículo. Conforme Al.11:

O currículo é um documento que tem por objetivo direcionar a formação que se pretende oferecer a um determinado público. Por exemplo, o currículo da educação básica direciona para uma formação que possibilite aos alunos, deste nível, viver como cidadãos na sociedade contemporânea.

Nas narrativas ainda sugerem o currículo como um documento que indica: a) os conteúdos que são necessários à aprendizagem do aluno em cada disciplina conforme o ano escolar; b) o Projeto Político Pedagógico (PPP) 
propondo as ações a serem desenvolvidas nos anos escolares, indicando os objetivos, conteúdos, metodologias, avaliação, bem como a gestão da escola e a formação continuada dos professores; c) os conhecimentos (conteúdos) e práticas com as dinâmicas para sua realização, atendendo algumas temáticas emergentes que surgem daquele contexto e situações daquela comunidade; e d) possibilidades para professores, gestão, coordenação, pais, funcionários e comunidade encontrar respostas para avançar no conhecimento, com acompanhamento e articulação com os pares e com diálogo. (MOREIRA, 2007)

Para os estudantes, o currículo apresenta-se como documentos no sentido de procurar "direcionar as ações que devem ser praticadas" (Al.09) e, também, com "objetivo de direcionar a formação que se pretende oferecer a um determinado público"(Al.11). Mostra-se, ainda, como "parâmetros necessários para a continuidade e desenvolvimento dos conteúdos mais aprofundados" (Al.01), os quais deverão ser "seguidos em determinada instituição de ensino" (Al.08). Já o estudante (Al.05) indica que o currículo pode ser considerado um "conjunto de informações organizadas, as quais permitem compreender (elou visualizar) as atividades realizadas por uma pessoa, ou ações a serem realizadas em um curso num período de tempo limitado". Esta narrativa indica o currículo como documento que deve ser seguido no intuito de organizar as disciplinas, apresentando uma estrutura rígida "contendo aquilo que será ofertado ao participante e o que se espera deles ao fim do curso" (Al.05).

Nesse contexto, ainda está presente a marca de um currículo distante do contexto das pessoas, das aprendizagens e culturas. Centraliza a sua organização com a ênfase em disciplinas. (FIGUEIREDO, 1981 apud PARAISO, 2010)

Currículo como lista de conteúdos

A organização do currículo tendo como base o conteúdo foi narrado pela maioria dos alunos. Apresentam ideias que induzem a pensar um currículo 
baseado apenas na rígida hierarquia de conteúdos que devem ser trabalhos na escola, como é possível observar nas seguintes narrativas: "organização dos conteúdos de cada disciplina, O que cada disciplina vai abordar, como será trabalhado cada conteúdo, em que sequência, enfim, toda a organização da estrutura da disciplina em termos de conteúdo" (Al.06). "Sequência de conteúdos previamente estipulada e normatizada seguindo-se uma ordem paulatina de desenvolvimento de raciocínio" (Al.01). Estes estudantes percebem o currículo de maneira restrita à apresentação dos conteúdos que precisam ser trabalhos no decorrer do ano letivo, em cada nível escolar, e em cada disciplina. Ideia clara na narrativa de (Al.17), o qual mostra que o currículo “[...] representa os conteúdos a serem trabalhados em determinado ano (série) por disciplina. Representa o conteúdo mínimo exigido para cada ano, assim unidade escolar e órgãos educacionais possuem os conteúdos organizados por disciplinas e por etapa escolar”.

A ideia do conteúdo como ponto forte na organização do currículo foi apresentada como objeto a ser ensinado pelo professor na perspectiva que será aprendido pelos alunos. Mas, aquelas perguntas sugeridas por Apple (2006) como: quais conteúdos/conhecimentos? Quem será privilegiado com esses conteúdos? Por que esses e não outros? Não se fizeram presente. Não evidenciou se na escola que lecionam essas perguntas permeiam a organização do currículo. Os conceitos centrais sugeridos por Giroux 'esfera pública, intelectual transformador e voz' (SILVA, 2005) não foram mencionados, principalmente a voz do aluno como objeto importante na constituição do currículo na transformação social e na formação, o seu lugar como participante ativo, sujeito de sua aprendizagem, na produção e criação de significados. Os conteúdos aparecem como algo abstrato e sem vida. Conteúdos organizados em sequência indicam uma ordem linear que não considera o movimento de ir e vir da sociedade.

Currículo como saberes e desenvolvimento de competências e habilidades 
Pensar o currículo como local de saberes e desenvolvimento de competências e habilidades foi narrado pelos alunos, considerando que essas competências são adquiridas na formação (MACEDO, 2009). No Dicionário Online de Português (2019) habilidade é definida como particularidade ou característica daquele que é hábil; capacidade, agilidade, destreza. Ao passo que competência, é definida como a capacidade decorrente de profundo conhecimento que alguém tem sobre um assunto, pode ser considerada o conjunto de habilidades, saberes e conhecimentos que determinada pessoa tem sobre um assunto (DICIO, 2019).

No entendimento dos estudantes, o currículo é o conjunto de competências e habilidades "[...] de um indivíduo interagir conscientemente na sociedade" (Al.04), e "[...] a serem desenvolvidas (ou melhoradas) durante um período de tempo pré-fixado" (Al.05). O estudante Al.10 entende o currículo [...] como a capacidade do aluno de mobilizar ou transmitir saberes, conhecimentos, habilidades e atitudes para resolver problemas e tomar decisões adequadas de um determinado problema da sociedade ou na vida". A partir destas narrativas, observa-se a preocupação desse estudante nas relações com a sociedade e na formação na vida e para a vida, talvez a proposta de currículo (MACEDO, 2009) seja um ponto de partida para atender a essa formação para a 'vida'. Certamente, o questionamento feito por VeigaNeto (2002) é uma ação de reflexão constante no contexto da escola para revisitar sempre o seu planejamento e as tomadas de decisão visando à mobilização de saberes, a resolução de problemas e as mudanças no mundo contemporâneo.

As narrativas dos estudantes de pós-graduação sobre as perspectivas sociais, políticas e inclusiva (Al.01), considerando a realidade cultural da comunidade (Al.02), sugere um currículo que direcione para a formação, que possibilite viver como cidadãos na sociedade contemporânea (Al.11). Essa preocupação instiga a pensar na constituição de um currículo que considere fatores regionais, culturais e sociais de cada localidade, para que as pessoas sejam formadas atuantes dentro de suas realidades (Al.11), corroborando com 
essas percepções dos estudantes. Para Madruga (2016, p. 256),

[...] faz-se necessário um currículo multicultural, que contemple a identidade dessas pessoas e dos seus fazeres, que se preocupe com a cultura popular e não a ignore, pois essa cultura, impregnada nas pessoas, influência de forma efetiva no desenvolvimento da criatividade do estudante. [...]. É importante que o currículo seja pensado e organizado de tal forma que contemple as identidades dos estudantes, para que eles possam explorar e mostrar o seu potencial criativo. Considera-se que o caminho não está em uma forma disciplinar e sim em olhar os problemas como um todo, ou seja, que o currículo busque visar os problemas da sociedade, daquela comunidade em específico para a qual está sendo construído. Dessa forma, o currículo não pode ser algo pronto, único, deve ser elaborado para cada grupo, cada comunidade, de uma forma muito particular.

Para (Al.25), "O currículo compreende a relação de competências e habilidades básicas a serem desenvolvidas no decorrer de uma etapa [...] considerando uma teoria ou conjunto de práticas pedagógicas que devem fundamentar uma matriz curricular, para que atenda o contexto em que professores e alunos estão inseridos". Na percepção desse estudante, o currículo direciona os fundamentos epistemológicos do conhecimento que precisam ser estudados nas diferentes disciplinas, e estabelece metas e objetivos para o desenvolvimento intelectual do educando no intuito de tornálo capaz de interpretar o mundo em que vive, em seus aspectos históricos, sociais, políticos e culturais.

Nessa direção o estudante (Al.26) menciona que: "[...] vale ressaltar que o contexto histórico impactua no currículo. Onde a escola do período tecnicista, por exemplo, preza a técnica e a escola nova, a reflexão".

Entre o desenvolvimento de competências e habilidades e a construção de saberes ficou evidenciado, nas narrativas, que os estudantes já vislumbram outras formas de currículo, principalmente para o ensino e 
aprendizagem de um saber matemático mais relacionado com o contexto e as diversas realidades. Começam a construir um pensamento sobre o currículo que une, distingue e é tecido junto (MORIN, 2003).

\section{Percepções sobre Currículo de Matemática}

O ponto central da pesquisa era perceber a relação/inter-relação que os alunos - na sua maioria, já professores - estabeleciam entre currículo e Matemática. Narraram, a partir de suas experiências e do local onde desenvolvem atividades profissionais, a maneira como percebem a organização do Currículo de Matemática.

Assim, quando se trata da disciplina específica (Matemática) tem-se a ideia que é uma área de conhecimento considerada "como algo frio, estanque, imposto e sem nexo social com a realidade emergente do aluno em sua fase de desenvolvimento, [fases de desenvolvimento], criando assim uma apatia em relação aos alunos e o interesse desses para com o estudo da matemática" (Al.08) e, ainda, “[...] não associada à realidade das escolas públicas, como currículo engessado, que não prioriza as diversidades culturais brasileiras" (Al.01). Nessa direção, D’Ambrosio (2001, p. 81) sugere que:

A educação formal, baseada na transmissão de explicações e teorias (ensino teórico e aulas expositivas) e no adestramento em técnicas e habilidades (ensino prático com exercícios repetitivos), é totalmente equivocada, como mostram os avanços mais recentes de nosso entendimento dos processos cognitivos. Não se pode avaliar habilidades cognitivas fora do contexto cultural. Obviamente, capacidade cognitiva é própria de cada indivíduo. Há estilos cognitivos que devem ser reconhecidos entre culturas distintas, no contexto intercultural, e também na mesma cultura, no contexto intracultural.

Situação que, ainda, indica a marca de um currículo baseado na teoria 
tradicional (SILVA, 2005), sem considerar o local, o aluno como sujeito ativo e o professor como mediador das situações de ensino e aprendizagem. "As escolas tradicionais têm tendência a valorizar uma situação escolar gerada por regras relativamente fixas (para manter a ordem). Os conhecimentos são ensinados em unidades discretas, pouco ligadas entre si, e a performance é avaliada por provas de memorização" (LUBART, 2007, p. 79). Embora apresente certo hibridismo de ideias, metodologias e formas de avaliação, a Matemática apresenta, "um currículo extenso e, por conta disso, torna-se enfadonho para o aluno a vastidão de conteúdo sendo que, por vezes, ele não entende a importância ou até mesmo a aplicação de tal conteúdo em sua vida" (Al.02). E ainda, o currículo de matemática "[...] leva em consideração essa descrição com um viés voltado para o campo da matemática”(Al.09).

A ideia de aplicação remete a uma das características da teoria tradicional do currículo, baseada no behaviorismo (Skinner) que propunha um saber-fazer para determinada ação. Essa ideia ainda aparece, na tentativa de buscar explicação para a abstração de alguns conteúdos matemáticos, principalmente quando a licenciatura ainda apresenta um tom de bacharelado.

Aqui vale uma reflexão: será que a Matemática ensinada tendo como base cálculos e expressões abstratas está fundamentada na teoria tradicional de currículo ou nos fundamentos de uma Matemática pura? Um questionamento que instiga a pensar na possibilidade de refletir sobre o ensino de Matemática fundamentado no behaviorismo e na perspectiva da Matemática pura. Nesse sentido, conforme Al.11, "o ensino e a aprendizagem do conteúdo matemático tendo como a base a Matemática pura também encanta”. Assim, a cada dia novas demandas vão surgindo para a pesquisa acadêmica e da docência, para avançar na construção do conhecimento, principalmente no que se refere ao campo da Educação Matemática.

O desenvolvimento das competências e habilidades para a formação crítica e cidadã mediadas pelo conteúdo matemático fez-se presente como caminho possível para fortalecer as relações sociais de poder em um território 
político para construir a identidade (SILVA, 2005), considerando a realidade e seus saberes, atendendo as diversidades, visto que a diferença por si só já está presente em cada sala de aula. Se há diferença, há diversidade e as formas de aprender, compreender o conteúdo matemático em determinado contexto, certamente, será diferente e deve ser objeto de análise. Assim, as narrativas evidenciaram que o currículo de Matemática deve: “[...] ser organizado de modo que possa formar tanto cidadãos para atuar em diversos seguimentos sociais quanto formar aqueles que pretendem enveredar-se para uma carreira científica. Cabe ressaltar aqui que o currículo de Matemática deve atender também a diversidade cultural, por isso a importância de atender a grande demanda da sociedade” (Al.05). E também "[...] que seja definido a partir da realidade dos alunos, ou seja, contextualizado"(Al.07).

Considerando a Matemática com objeto de ensino e aprendizagem, de maneira sutil, as indicações de desenvolvimento de competências e habilidades, sugeridas nas Diretrizes Curriculares para o curso de Matemática, e a perspectiva interdisciplinar foram mencionadas nas narrativas dos alunos quando sugeriram a tomada de decisão, um trabalho interdisciplinar com as demais áreas do conhecimento na interface com a Matemática, a formulação e resolução de problemas (BRASIL, 2001). Para Al.10, "É importante, lembrar que o currículo de matemática deve estar ligado aos demais currículo, ou seja, ao de português, geografia, história, entre outras. Trabalhando de forma conjunta, poderá permitir ao aluno uma melhor tomada de decisões". Nesses termos, Madruga e Biembengut (2016) consideram que o conhecimento precisa ser desenvolvido de tal forma a ser inter/transdisciplinar.

$\mathrm{Na}$ Educação formal, em todos os níveis, a estrutura é organizada em áreas e, cada área, em um conjunto de disciplinas. O programa curricular de cada disciplina nesta estrutura é dividido em diversos tópicos que, pela forma expressa, não se 'mostram' elos entre uma e outra disciplina. Perpassado entre estas disciplinas, tópicos e currículo, encontra-se o processo pedagógico: 'ensino', 
'aprendizagem' e 'avaliação'. Avaliação do professor em relação ao estudante, do estudante em relação ao professor e do sistema em relação ao estudante, por meio dos indicadores nacionais e internacionais. (MADRUGA; BIEMBENGUT, 2016, p. 21-22)

O currículo escolar não pode ser considerado um instrumento "inocente e neutro de transmissão desinteressada do conhecimento social" (MOREIRA; TADEU, 2011, p. 14), pois é um produto da cultura e da sociedade. "Sendo assim, os elementos que compõem o currículo tratam-se do produto de uma seleção intencional, um recorte o qual se espera atender determinadas expectativas, sejam elas em linhas mais tradicionais ou críticas". (MADRUGA; GALLON; SILVA, 2016, p. 118)

De acordo com Madruga e Biembengut (2016), os documentos oficiais promulgam que o currículo seja organizado de tal forma que propicie ao estudante, em qualquer etapa de escolaridade: o desenvolvimento da formação ética; da autonomia intelectual; e do pensamento crítico. Além da compreensão dos fundamentos científicos e tecnológicos, bem como dos processos produtivos, onde se relaciona a prática com a teoria, no ensino de cada disciplina.

A forma de aprender para ensinar também é revelada como uma ação do currículo, considerando que na escola a formação do professor também é ação curricular. Problematizar o ensino, a aprendizagem e a formação é uma possibilidade de olhar, escutar, refletir e compreender as novas 'formas' (geometrias) (VEIGA-NETO, 2002), superando a abstração e dando ênfase à pessoa que aprende, a sua capacidade de iniciativa e de seu espírito de competitividade (PARAISO, 2010), atendendo as necessidades de uma sociedade tecnologizada.

\section{Conclusão}

Este artigo teve como objetivo compreender como estudantes de pósgraduação em Educação Matemática percebem o currículo, no contexto do 
próprio currículo e nas suas relações com o ensino e a aprendizagem de Matemática. Compreender essas relações com o ensino e a aprendizagem é uma tarefa que ainda requer aprofundamento nas reflexões e acompanhamento das ações desses alunos visto que continuam em um processo de formação (pós-graduação).

Talvez, alguns questionamentos sejam necessários para se avançar nas discussões sobre currículo e a Matemática. Duas temáticas que, por si só, possuem um caráter abstrato, mas precisam ser contextualizados para dar sentido e significado a partir da realidade social, política e cultural daqueles que dão voz a essa ação (professor-aluno-comunidade), valorizando as geometrias do currículo (VEIGA-NETO, 2002) e a produção de situações híbridas (LOPES; MACEDO, 2011) nos aspectos culturais, sociais e políticos.

Os dados mostraram que a maioria dos estudantes da pós-graduação, colaboradores desta pesquisa, percebem o currículo como: 1) um conjunto de documentos que orientam as ações do professor em sala de aula; 2) uma lista de conteúdo a ser trabalhado nas instituições de ensino; e 3) um conjunto de competências e habilidades a serem desenvolvidos. No que tange ao currículo de Matemática os estudantes percebem-no de forma rígida, não contemplando a diversidade social e cultural.

O currículo de Matemática, assim como os das demais disciplinas, precisa ser pensado e organizado de forma com que contemple as identidades dos educandos, para que os mesmos possam relacionar os conteúdos com a sua realidade, respeitando cada região e localidade, a cultura e a diferença. Desse modo, o currículo não pode ser algo único, imposto por esferas superiores, e disciplinar, mas que busque visar os problemas da sociedade, das comunidades e grupos para as quais está sendo elaborado, seguindo o movimento da sociedade e do local da escola/comunidade com suas várias geometrias (VEIGA-NETO, 2002), desenvolvendo competência de natureza cognitiva, afetiva, prática e conativa (PAQUAY et al, 2001), de uma maneira muito particular, para evitar prejuízo epistemológico e formativo para professores e alunos (MACEDO, 2009). 


\section{Referências}

APPLE, M. W. A política do conhecimento oficial: faz sentido a ideia de um currículo nacional? In: MOREIRA, A. F. B.; SILVA, T. T. da. Currículo, Cultura e Sociedade. 9 , São Paulo: Cortez, 2006.

BEHRENS, Marilda Aparecida. O paradigma emergente e a prática pedagógica. $5^{\text {a }}$ ed, Rio de Janeiro: Vozes, 2011.

BIEMBENGUT, M. S. Modelagem Matemática no Ensino Fundamental. Blumenau: Editora da FURB, 2014.

BOGDAN, R.; BIKLEN, S. Investigação Qualitativa em Educação. Porto, Portugal: Editora Porto, 2010.

BRASIL. Parecer CNE/CES 1.302/2001. Diretrizes Curriculares Nacionais para os Cursos de Matemática, Bacharelado e Licenciatura, 2001.

D’AMBROSIO, U. Etnomatemática. Elo entre as tradições e a modernidade. Belo Horizonte: Autêntica, 2001.

DICIO. Dicionário Online de Português. Disponível em: < https://www.dicio.com.br/> Acesso em 11 jul. 2019.

DEWEY, John. Vida e educação. Tradução de Anísio S. Teixeira. $7^{\mathrm{a}}$ ed, São Paulo: Edições Melhoramentos, 1971.

GEORGE, F. Modelos de Pensamentos. Trad. Mário Guerreiro. Petrópolis, RJ: Vozes, 1973.

KILPATRICK, J. Investigación em educación matemática: su historia y algunos temas de actualidad. In: KILPATRICK, J.; GÓMEZ, P.; RICO, L. Educación Matemática: Errores y dificultades de lós Estudiantes. Resolución de problemas. Evaluación. Historia. Bogotá: Universidad de lós Andes, 1998. p. 1-18.

LOPES, A. C.; MACEDO, E. Teorias de Currículo. São Paulo: Cortez, 2011.

LUBART, T. Psicologia da criatividade. Trad. Márcia Conceição Machado Moraes. Porto Alegre: Artmed, 2007.

MACEDO, R. S. Currículo: campo, conceito e pesquisa. 3ª ed. Petrópolis: Vozes, 2009.

MADRUGA, Z. E. F. Processos criativos e valorização da cultura: possibilidades de aprender com modelagem. Tese (Doutorado em Educação em Ciências e Matemática). Pontifícia Universidade Católica do Rio Grande do Sul, Porto Alegre, 2016.

MADRUGA, Z. E. F.; BIEMBENGUT, M. S. Modelagem \& Aleg(o)rias: um enredo entre Cultura e Educação. Editora Appris, 2016.

MADRUGA, Z. E. F.; GALLON, M. S.; SILVA, C. M. Criatividade e 
Transdisciplinaridade: reflexões acerca de suas contribuições à educação. Revista de Educação Dom Alberto n. 9, v. 1, jan./jul. 2016.

MARIOTTI, H. Os operadores cognitivos do pensamento complexo. 2007.

Disponível em < http://pavoniking.hospedagemdesites.ws/imagens/trabalhosfoto/402007 operadores. pdf> Acesso em 10 jul. 2019.

MORAES, M. C. Tecendo a rede, mas com que paradigma? In. MORAES, M. C. Educação a Distância: fundamentos e práticas. Campinas: Unicamp/Nied, 2002.

MORAES, R. Uma tempestade de luz: a compreensão possibilitada pela análise textual discursiva. In: Ciência \& Educação, v.9, n.2, p. 191-211, 2003.

MORAES, R.; GALIAZZI, M. C. Análise Textual Discursiva. 2ed. Ijuí: Editora Unijuí: 2013.

MOREIRA, A. F. B. Indagações sobre currículo: currículo, conhecimento e cultura. Organização do documento Jeanete Beauchamp, Sandra Denise Pagel, Aricélia Ribeiro do Nascimento. Brasília: Ministério da Educação, Secretaria de Educação Básica, 2007.

MOREIRA, A. F. B.; TADEU, T. Sociologia e teoria crítica do currículo: uma introdução. In: MOREIRA, A. F. B.; TADEU, T. (Orgs.) Currículo, cultura e Sociedade. 12. ed. São Paulo: Cortez. p. 7-12.

MORIN, E. A cabeça bem-feita: repensar a reforma, reformar o pensamento. Trad. Eloá Jacobina. $8^{a}$ ed. Rio de Janeiro: Bertrand Brasil, 2003.

PAQUAY, L.; PERRENOUD. P.; ALTET, M.; CHARLIER, E. Formando professores profissionais: três conjuntos de questões. In: PAQUAY, L.; PERRENOUD. P.; ALTET, M.; CHARLIER, E. Formando professores profissionais. Quais estratégias? Quais competências? 2a ed, Porto Alegre: ArTmed, 2001.

PARAÍSO, M. A. (Org.). Antonio Flávio Barbosa Moreira. Pesquisador em Currículo. Belo Horizonte: Autêntica Editora, 2010.

PIRES, C. L. C; GODOY, E. V.; SILVA, M. A.; SANTOS, V. M. O currículo de Matemática em revista: um editorial. In: Bolema, Rio Claro (SP), v. 28, n. 49, p. 485490, ago. 2014.

SILVA, T. T. da. Documentos de Identidade. Uma introdução às teorias de currículo. Belo Horizonte: Autêntica, 2005.

VEIGA-NETO, A. De geometrias, currículos e diferenças. In: Educação \& Sociedade. ano XXIII, $\mathrm{n}^{\circ} 79$, agosto/2002. 